\title{
Anápolis: a refuncionalização da cidade média e o papel dos planos diretores
}

\section{Anápolis: la refuncionalización de la ciudad media y el papel de los planes directores}

\author{
Anápolis: the re-functioning of the medium sized city and the \\ role of Master Plans
}

\author{
Letícia Pacheco dos Passos Claro \\ leticiaclaro@hotmail.com \\ Universidade de Brasília, UnB, Brasília, DF
}

\begin{abstract}
Resumo: Essa pesquisa busca explorar o processo de refuncionalização de uma cidade média com centralidade na rede urbana pela lente dos planos diretores da cidade e compreender o papel dessas políticas para as transformações do território. A refuncionalização é fruto de intencionalidades e disputas de poder entre atores que legitimam suas ações nas políticas públicas. Portanto, explorar esse processo pela ótica dos planos parte da ideia central do papel destes em direcionar, induzir ou modificar os usos do território. Dessa forma, esse estudo trata da narrativa histórica da formação da cidade até os dias atuais em paralelo com a história narrada pelos planos diretores evidenciando os caminhos da refuncionalização de Anápolis. Nesse caminho é possível observar as transformações econômicas da cidade, passando da exploração comercial e pequenos serviços de escoamento da produção local, à especialização do setor industrial e de serviços ligados ao transporte logístico em escala regional. Os planos diretores têm um papel fundamental no direcionamento à essa refuncionalização, além de terem relação direta com o contexto, especialmente nos momentos de crise local/nacional, especialmente com objetivo de manter a cidade como polo atrator de investimentos e centralidade na sua rede urbana.
\end{abstract}

Palavras-chave: espaço; políticas públicas; processos; formas; funções; estruturas.

Resumen: Esta investigación busca explorar el proceso de refuncionalización de una ciudad media con centralidad en la red urbana por la lente de los planes directores de la ciudad y comprender el papel de esas políticas para las transformaciones del territorio. La refuncionalización es fruto de intencionalidades y disputas de poder entre actores que legitiman sus acciones en las políticas públicas. Por lo tanto, explorar este proceso por la óptica de los planes parte de la idea central del papel de éstos en dirigir, inducir o modificar los usos del territorio. De esta forma, este estudio trata de la narrativa histórica de la formación de la ciudad hasta los días actuales en paralelo con la historia narrada por los planes directores evidenciando los caminos de la refuncionalización de Anápolis. De esta manera, es posible observar las transformaciones económicas de la ciudad, desde la explotación comercial y pequeños servicios para flujo de la producción local, hasta la especialización del sector industrial y los servicios relacionados con el transporte logístico a escala regional. Los planes directores juegan un papel fundamental en la dirección de esta refuncionalización, además de estar directamente relacionados con el contexto, especialmente en tiempos de crisis local / nacional, especialmente con el objetivo de mantener a la ciudad como un atractor de inversiones y centralidad en su red urbana.

Palabras clave: espacio; políticas públicas; procesos; formas; funciones; estructuras. 
Abstract: This research seeks to explore the process of re-functioning of a mediumsized city, the centrality of its urban network, by the lens of the city's director plans and to understand the role of these policies for the transformations of the territory. The re-functioning is the result of intentionalities, and power disputes between actors who legitimize their actions through public policies. Therefore, exploring this process from the point of view of plans starts from the central idea of their role in directing, inducing or modifying the uses of the territory. Thus, this study deals with the historical narrative from the formation of the city up to the present day in parallel with the history told by the director plans evidencing the paths through the re-functioning of Anápolis. Thus, it is possible to observe the economic transformations of the city, from commercial exploitation and small services of local production flow to the specialization of the industrial sector and services related to logistic transportation at a regional level. The director plans to play a fundamental role in leading this re-functionalization, also it is directly related to the context, especially in times of local/national crisis, mainly with the objective of keeping the city as an attractive investment and centrality in its urban network.

Key words: space; public policies; processes; forms; functions; structures.

\section{INTRODUÇÃO}

A temática urbana é multidisciplinar, por envolver diferentes disciplinas, e também transdisciplinar, pois permeia não só as disciplinas como aspectos da realidade que não podem e nem devem se limitar ao campo disciplinar. Uma visão fragmentada faz com que diversos aspectos da realidade, extremamente complexa, não sejam abarcados nos estudos urbanos. Partindo dessa premissa, a teoria espacial miltoniana trata do espaço totalidade, da sociedade em movimento e da natureza relacional dos elementos e categorias do espaço.

Entender o espaço totalidade é o primeiro passo ao explorar a questão urbana. O espaço não se limita ao percebido por uma dada sociedade, nem é uma soma de frações, e sim a interação constante de sistemas de objetos e de ações que, por meio de técnicas, transformam o território ao longo do tempo. Logo, falar da totalidade é entender as transformações nas escalas tanto interurbanas quanto intraurbanas, entender que a maneira como o território é usado depende tanto de características internas e externas a esse território e, especialmente, da sociedade em movimento. Essa pesquisa parte da compreensão do espaço totalidade, do entendimento das limitações da visão do pesquisador e, portanto, da possibilidade de acesso apenas a frações do território e a um aspecto limitado das influências sofridas por esse recorte territorial.

Nesse sentido, a viabilidade desse estudo só se concretiza ao se definir um objeto e a forma de se olhar para ele - a cidade de Anápolis, em Goiàs, é o objeto e o olhar é o processo de refuncionalização, ou seja, transformações das funções urbanas da cidade pela narrativa histórica em sete períodos (1887 a 1930, 1930 a 1950, 1950 a 1970, 1970 a 1990, 1990 a 2000, 2000 a 2010, 2010 a 2018) pela lente dos cinco planos diretores da cidade (1969, 1985, 1992, 2006 e 2016).

As categorias miltonianas de análise do espaço - processos, formas, funções e estruturas - são a base para o entendimento do espaço totalidade, e permitiram observar 
as interações entre pessoas, objetos e instrumentos em Anápolis com o passar dos anos. Essas categorias são exploradas em um primeiro momento no estudo da narrativa histórica a fim de traçar o panorama das principais transformações do território anapolino.

Uma vez que as interações e relações de poder entre agentes revelam a dinâmica do espaço geográfico, as políticas públicas são vistas como importantes instrumentos para usos e usuários do território. O plano diretor é, segundo os atuais marcos legais da política urbana, o instrumento básico desta política, e tem papel fundamental em direcionar, modificar, inibir ou induzir os usos do território, portanto, faz-se o segundo pilar analítico da pesquisa.

A análise dos planos diretores busca identificar atores, setores beneficiados, ideologias dominantes e direcionamento da política a partir de três eixos: (i) estratégias para o desenvolvimento local, (ii) uso e ocupação do solo e complementariedade e (iii) aplicação da política urbana. $\mathrm{O}$ estudo integrado da narrativa histórica e do direcionamento dos planos diretores permitiu traçar o panorama da refuncionalização de Anápolis.

\section{ESPAÇO GEOGRÁFICO E REFUNCIONALIZAÇÃO}

Tratar da questão urbana é compreender que esta é uma questão sistêmica que se dá a partir de interações e conflitos entre atores, ou seja, da sociedade em movimento da teoria miltoniana, da vida que anima, ou seja, o princípio ativo desses objetos, que produz espaço.

Para Santos (2014, p.30), o espaço “deve ser considerado como um conjunto indissociável, de que participam, de um lado, certo arranjo de objetos geográficos, objetos naturais e objetos sociais e, de outro, a vida que os preenche e os anima, ou seja, a sociedade em movimento". Isso significa dizer que o espaço é também um fator da evolução social, logo tratar da questão urbana é tratar do território que é usado e transformado pela ação humana.

Santos (1985), para o espaço totalidade, define as seguintes categorias de análise que conformam o método geográfico: processos, funções, formas e estruturas. 'Processo' está relacionado à ação contínua; 'Estrutura' à interrelação das partes com o todo; 'Forma' diz respeito ao aspecto visível de uma coisa, ao arranjo ordenado de objetos; e 'Função' à atividade esperada de uma forma. Ainda, somam-se à essas categorias os chamados elementos que compõem o espaço: os homens, as instituições, as firmas, o meio ecológico e a infraestrutura (SANTOS, 1985, p. 6). Ainda segundo Santos (1985, p. 7) o "[...] estudo das interações entre os diversos elementos do espaço é um dado fundamental da análise", sendo a ideia de tempo uma constância dessas interações. Ou seja, o autor defende que o movimento da história tem um papel central na mudança de valor dos elementos do espaço.

Além dos elementos, o autor descreve a técnica como outra variável de grande importância para a análise das transformações espaciais. Para Santos (1985, p. 13) “[...] cada lugar é uma combinação de técnicas qualitativamente diferentes, individualmente dotadas 
de um tempo específico" e todas as variáveis estão conectadas por uma organização, ou seja, por um conjunto de normas destinadas a

[...] prolongar a vigência de uma dada função, de maneira a lhe atribuir uma continuidade e regularidade que sejam favoráveis aos detentores do controle da organização. Isso se dá através de diversos instrumentos de efeito compensatório que, em face da evolução própria dos conjuntos locais de variáveis, exercem um papel de regulador, de modo a privilegiar um certo número de agentes sociais (SANTOS, 1985, p. 13).

Isto evidencia o caráter político das relações e interações dos elementos do espaço conformando um sistema comandado por um modo de produção dominante. Cada sistema é composto por um mosaico de elementos e variáveis que se alteram ao longo do tempo, isto é, cada momento evidencia características do funcionamento do sistema dominante. A dinâmica das organizações permite observar as transformações do território rumo à especialização dos lugares, à criação de lugares privilegiados e polarizados, além de evidenciar as possibilidades de dominação a partir da localidade.

O estudo de processos, estruturas, formas e funções possibilita compreender as transformações do território ao longo do tempo. Essas categorias são de natureza relacional e não podem ser entendidas em si mesmas, é a interação entre elas que confere uma visão de uma fração espacial, logo, tratar da refuncionalização de Anápolis é, de certa forma, conversar com todas as categorias e compreender suas interações com as variáveis e elementos do espaço, essa totalidade que modifica processos, os quais exigem novas funções e dão novos valores às formas (SANTOS, 1985). Ainda para Santos (1985), as formas compõem camadas de tempos passados, sendo parte de um sistema e de um relato das estruturas a qual serviram. Formas são criadas para executar funções que são regidas por uma organização em um determinado contexto histórico, logo, a refuncionalização é aqui entendida como mudanças das funções urbanas devido às imposições das variadas organizações que foram emergindo.

\section{POLÍTICAS PÚBLICAS, PLANEJAMENTO URBANO E PLANO DIRETOR}

Espaço é o locus da produção e é constantemente transformado e adequado a novos usos. A produtividade de um determinado local depende dessa adequação do território, da mudança de suas formas e funções. Ainda, é necessário compreender que na atual conjuntura produtiva, não é possível mais tratar de cidades isoladamente e sim de um conjunto de cidades que se articulam e se complementam no processo produtivo.

O desenvolvimento do meio técnico-científico-informacional possibilitou o aumento da circulação de informações e possibilitou condições para ampliar a especialização do trabalho nos lugares. Segundo Santos e Silveira (2003, p. 105) “cada ponto do território modernizado é chamado a oferecer aptidões específicas à produção", sendo que lugares mais competitivos e aptos se mantêm ativos no cenário produtivo. 
Mark Gottdiener (1997, p. 16) trata das relações de poder que transformam o território e defende que a sociedade tem um papel central que pode " produzir e manter (ou reproduzir) [...] padrões do uso da terra". Para o autor, essas transformações dependem de forças sociais, especialmente as relações "hierarquicamente estruturadas a processos de sistema global, como a acumulação de capital e a nova divisão internacional do trabalho" (GOTTDIENER, 1997, p. 17). Essa afirmativa, do papel das relações sociais na transformação do território vai de encontro com o pensamento miltoniano, da necessidade da sociedade em movimento para a produção de espaço.

Em se tratando de relações "hierarquicamente estruturadas" é importante abordar o papel das políticas públicas e especialmente do planejamento urbano nesse contexto. A teoria clássica de políticas públicas entende que a ação política está centralizada nas mãos do Estado, o que levou muitas vezes ao entendimento de que política pública era uma ação de Estado, visando a um bem comum e sem a interferência de outros atores. Segundo Lascoumes e Le Gales (2012) esse modelo clássico de políticas públicas está ultrapassado, principalmente pela atuação de outros atores locais - não inseridos na estrutura do Estado - como outras influências que ultrapassam o cenário local e nacional. Para isso, os autores introduzem a expressão 'ação pública' em substituição ao termo política pública uma vez que esta é uma produção essencialmente coletiva. Para Lascoumes e Le Gales, a ação pública está ligada a articulação de regulações sociais de políticas, conflitos variados, atividades políticas e também a questões de legitimidade dos atores, ou seja, eles apontam como políticas são utilizadas para defender interesses e legitimar a ação de determinados atores, sejam eles do âmbito estatal ou não.

Gomes, Steinberger e Barbosa (2013) discutem, pautados no pensamento miltoniano, o potencial político da categoria 'território usado' empregada no estudo das políticas públicas. Para os autores, políticas públicas "mais do que implantadas no território, acabam por indicar, direcionar ou redirecionar os usos do território" (GOMES; STEINBERGER; BARBOSA, 2013, p. 66). Ainda segundo os autores, é o uso do território por todos os agentes que produz espaço, porém as relações de poder são constituídas de horizontalidades e verticalidades, sendo os agentes hegemônicos aqueles com maior mobilidade para os usos do território. Essa afirmativa concorda com Gottdiener e evidencia que as políticas públicas são instrumentos para usos e usuários do território, inseridas em um contexto de intensas disputas de poder entre diferentes atores - e não somente o Estado - que direcionam transformações nas cidades.

Dessa forma, quebrar o paradigma do Estado imparcial e que elabora políticas visando ao bem comum, respondendo a problemas da sociedade foi de extrema importância para reconhecer um campo de intensos conflitos, de intencionalidades e, especialmente, de jogos de poder. Nesse contexto, o planejamento urbano se mostra como uma variável de extrema importância para o estudo da cidade no universo da ação pública.

Phillip Allmendinger (2002) defende que toda teoria está inserida em uma formação de discurso e que teoria nas ciências sociais não está imune da influência do poder. Para esse autor, as teorias de planejamento têm implicações nos caminhos que o planejamento deve seguir para empoderar determinados grupos, portanto, o planejamento é sempre político 
e temporal. Allmendinger, como Gottdiener, considera que as transformações espaciais se dão por ações de forças sistêmicas as quais estão imbricadas nos modos de organização social. Para Gottdiener (1997, p. 28) “o planejamento urbano em toda sociedade é uma fachada para o poder", ou seja, compreender as transformações do território é observar também como o planejamento urbano foi sendo explorado ideologicamente.

A figura do plano diretor é de grande importância para o planejamento urbano brasileiro desde o início do século XX (VILLAÇA, 2015). Villaça defende cinco modalidades de planos no planejamento brasileiro: (i) os planos de embelezamento feito até os anos 1930; (ii) os planos técnicos ou de base científica da década de 1940; (iii) os superplanos da década de 1960; (iv) os planos enxutos e para posterior detalhamento de 1970 e (v) pós Constituição Federal de 1988 e Estatuto da Cidade, o plano diretor participativo.

O plano diretor estabelece os objetivos da política urbana e a maneira com que esses objetivos serão alcançados. Visa a sistematização do que se pretende para o desenvolvimento econômico, social e físico de um município. Ele é um instrumento indutor e regulador das transformações urbanas e resultado de uma arena de conflitos e disputas de poder em diferentes escalas. Dessa forma, explorar a refuncionalização impulsionada pelos planos diretores é investigar a história narrada por essas políticas, seus objetivos e direcionamentos que priorizam determinadas funções.

\section{REDES URBANAS E CIDADES MÉDIAS}

A urbanização brasileira se deu de maneira fragmentada e disforme, por meio de zonas econômicas que fizeram emergir uma legião de cidades, segundo Santos e Silveira (2003, p. 31), testemunhos de uma série de divisões territoriais do trabalho "fundadas em graus diversos de tecnificação". De acordo com os autores, o início do processo de urbanização brasileiro se assemelha a um arquipélago pelo surgimento de diversos conjuntos de cidades - do ouro, do diamante, das estradas de ferro, de passagem, etc. desconexas. Somente com o desenvolvimento dos transportes e comunicações que essas manchas começam a se conectar, "criando-se as bases para uma integração do território" (SANTOS; SILVEIRA, 2003, p. 31).

A difusão do meio técnico-científico-informacional tem início na década de 1970, caracterizando um período de revolução nas telecomunicações e de esforço para a integração do território. Esse esforço contribui para um pesado investimento em infraestruturas, implantação de complexos industriais - frutos da política de desconcentração industrial - e ampliação das redes de transporte e comunicação. A difusão do meio técnico-científicoinformacional permitiu melhor integração entre os centros urbanos e também a diversificação produtiva, permitindo maior crescimento para as metrópoles brasileiras e também das periferias econômicas e centros médios do país, complexificando a rede urbana nacional.

Segundo IPEA (2002, p. 20) essa rede:

[...] compreende o conjunto das cidades que polarizam o território brasileiro e os fluxos de bens, pessoas e serviços que se estabelecem entre elas. Em uma visão simplificada, 
é formada por centros, com dimensões variadas, que estabelecem relações dinâmicas entre si com campos de forças de diferentes magnitudes. São essas interações que respondem não apenas pela atual conformação espacial da rede, mas também por sua evolução futura, cuja compreensão é fundamental para o estabelecimento de metas de políticas públicas de desenvolvimento.

A área de influência de uma cidade revela o seu grau de importância, e essa hierarquia é o que Santos e Silveira (2003) definem como 'espaços do mandar' e 'espaços do obedecer'. Ou seja, o acúmulo de funções diretoras que é subsidiado por infraestruturas, insumos técnicos, políticos e pessoas diferencia espaços do 'mandar' e do 'obedecer'. É na perspectiva do papel hierárquico de cidades e a relevância na rede urbana que as cidades médias são aqui entendidas.

Corrêa (2017, p. 29) defende a noção de cidade média como de natureza relacional, "envolvendo relações com centros menores e maiores do que ela". Dessa forma, ela só pode ser entendida "como parte integrante de uma rede urbana" (CORRÊA, 2017, p. 29). Essas cidades são centros de serviços e mercado regionais ou especializados e articula territórios, são pontos nodais definidos pela convergência de fluxos com a função de intermediação na rede urbana. Ainda segundo Corrêa, a inserção de uma cidade média nas redes urbanas depende de fatores como suas funções urbanas, relações espaciais e papel das elites, sendo que a combinação desses fatores "gera uma complexa tipologia de centros" (CORRÊAA, 2017, p. 30).

A cidade média é entendida aqui como aquela que desempenha um papel de intermediação na rede urbana. Para Spósito e Góes (2013) essas cidades são importantes sob a ótica da divisão técnica e econômica do espaço, uma vez que integram e complementam os fluxos das redes, exigindo maior fluidez (transporte e comunicações) entre as cidades. Consequentemente, essa relação da escala interurbana redefine e complexifica a divisão técnica na escala intraurbana. Silveira (2017, p. 40) reforça esse argumento ao defender que cada divisão territorial do trabalho contribui para uma "geografia diversa da produção e do consumo", para mudanças nas formas e funções das cidades e mudanças na hierarquia dos centros urbanos nas redes. A autora defende ainda, que a compreensão das cidades médias depende do contexto histórico que constantemente altera seus papeis de acordo com a divisão territorial do trabalho. Essas são cidades que se refuncionalizam segundo as demandas da divisão territorial e social do trabalho para se manterem ativas na rede urbana.

\section{BASE METODOLÓGICA PARA O ESTUDO DE REFUNCIONALIZAÇÃO}

Essa pesquisa explorou apenas os textos das leis dos planos diretores, enquanto versão final utilizada e aplicada no dia a dia dos municípios, em paralelo com o resgate histórico dividido em sete períodos da história Anapolina: de 1887 a 1930, de 1930 a 1950, de 1950 a 1970, de 1970 a 1990, de 1990 a 2000, de 2000 a 2010 e de 2010 a 2018. Foram exploradas as quatro categorias miltonianas de análise do espaço a partir da narrativa histórica e, em 
seguida, analisados os cinco planos diretores de Anápolis (1969, 1985, 1992, 2006 e 2016) com objetivo de elucidar e compreender o processo de refuncionalização da cidade.

Pautada no estudo do Projeto Rede Nacional de Avaliação e Capacitação para Implementação dos Planos Diretores Participativos (SANTOS JUNIOR; MONTANDON, 2011), que levantou a necessidade de se avaliar qualitativamente os planos diretores das cidades brasileiras pós-Estatuto da Cidade, para a análise dos planos diretores elaborou-se um checklist com a definição de três eixos com critérios específicos para serem analisados e comparados nos cinco planos: (a) estratégias para o desenvolvimento local; (b) uso e ocupação do solo; e (c) complementariedade e aplicação da política urbana.

O objetivo do primeiro eixo é explorar os principais atores envolvidos na elaboração dos planos, o contexto e as estratégias dos planos, ou seja, as intencionalidades e ideologias do plano; o segundo eixo explora as estratégias de uso e ocupação do solo, com objetivo de definir quais setores e classes beneficiados e priorizados; o último eixo permite observar a interface com demais políticas e caracterizar a aplicação da política urbana no município. Por meio desse checklist é possível, de maneira sistematizada, fazer um comparativo dos planos e dos períodos e traçar o panorama da refuncionalização de Anápolis.

\section{Anápolis e os caminhos da refuncionalização}

Anápolis é uma cidade média localizada na região centro-oeste, no estado de Goiás (Fig. 1). Com população estimada de 375.142 habitantes, o município é parte da Mesorregião Centro Goiano, a mais rica e densa das mesorregiões goianas. Anápolis é beneficiada pela localização estratégica e chama a atenção pelo dinamismo econômico, principais características do seu processo de refuncionalização.

Figura 1: Localização de Anápolis, GO.

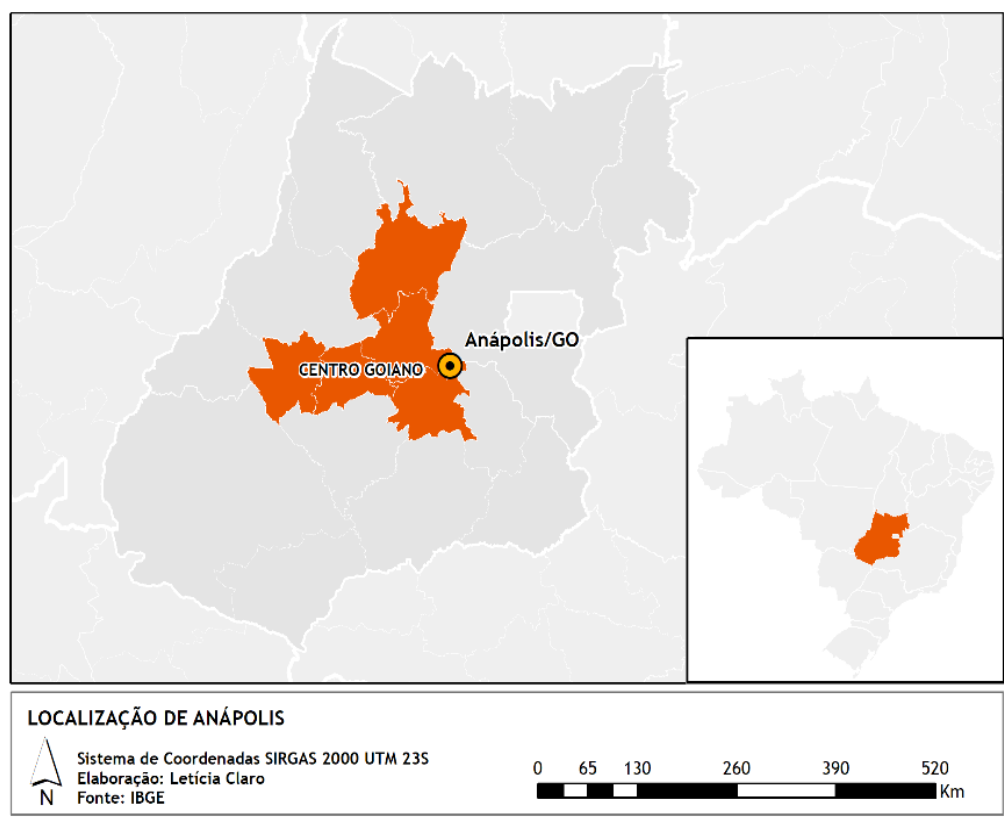

Fonte: adapt. de IBGE, 2018. 
A cidade está localizada na convergência de importantes rodovias que conectam diferentes regiões do país, além de ser um importante ponto de suporte no eixo BrasíliaGoiânia (Fig. 2). A cidade é uma das maiores economias do estado, destacando-se nos setores de serviços, comércio e indústria de transformação.

Figura 2: Eixo Goiânia-Anápolis-Brasília.

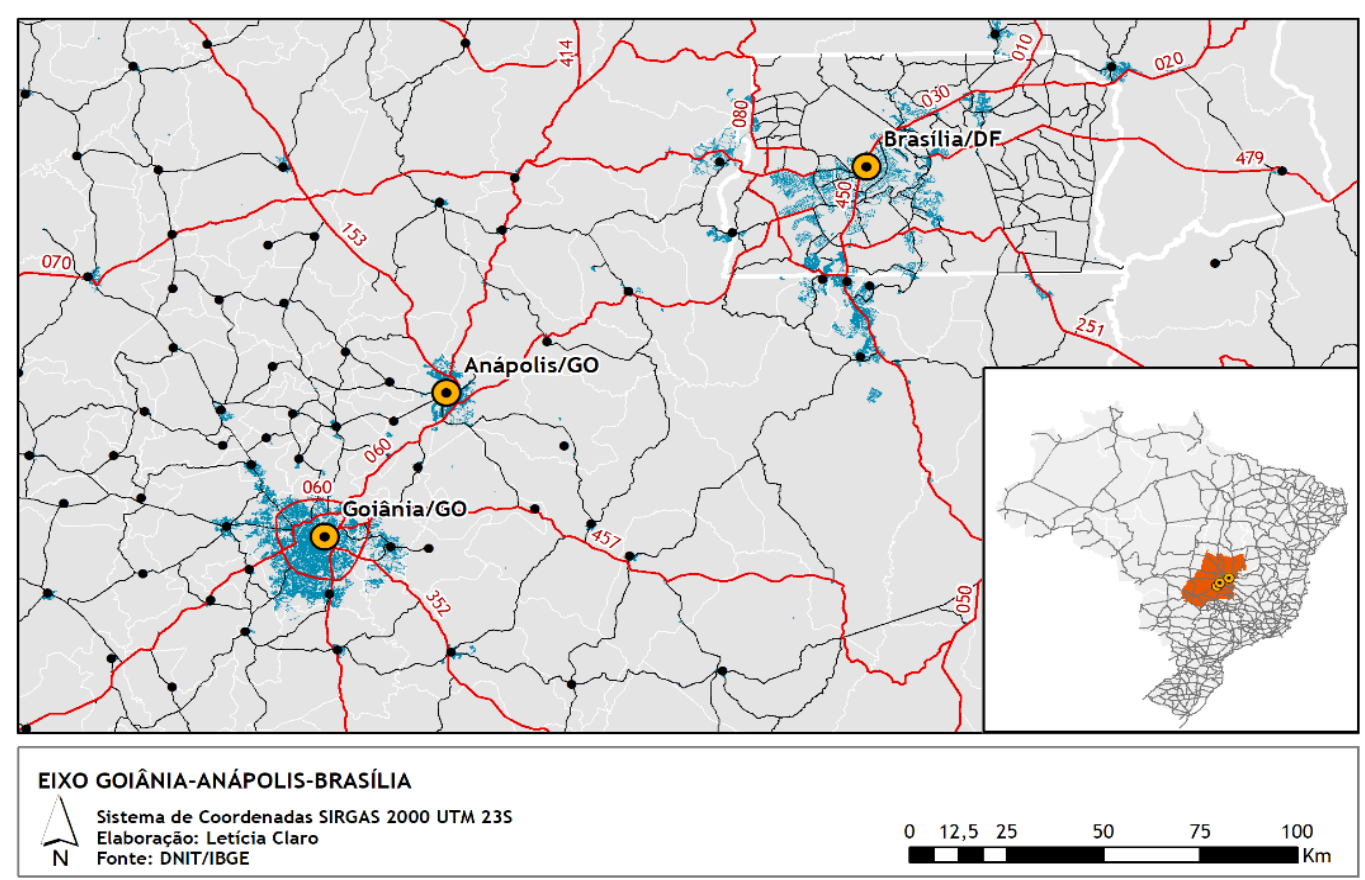

Fonte: DNIT e IBGE, 2018.

A refuncionalização anapolina foi intensa e a proximidade com as capitais Brasília e Goiânia tem um importante papel nesse processo. A implantação de obras de infraestrutura e os investimentos do governo federal e estadual são marcos dessa refuncionalização e hoje é uma cidade que se destaca pela atividade industrial e esforço de consolidação como centro logístico pela exploração de sua localização estratégica.

A origem de Anápolis data de 1871 como entreposto das rotas comerciais das cidades auríferas goianas. As características físicas propícias a agricultura e pecuária permitiram a fixação das pessoas e logo deu início a aglomeração urbana. O caráter dispersivo da região aos poucos foi sendo quebrado pela penetração da linha férrea, permitindo a expansão da fronteira agrícola e o crescimento do povoado de Santana das Antas. É no período da República Velha que Anápolis se estrutura e consolida como cidade, nesse período, a forte atuação das elites locais teve um papel de extrema importância para a instalação de infraestruturas na cidade (Fig. 3).

Na década de 1930, a ascensão de Pedro Ludovico ao estado goiano apoiado pela ideologia da modernidade significou a derrota das oligarquias locais. O discurso da modernidade foi bastante explorado nesse período e, com a ajuda das elites locais, permitiu a expansão e chegada da ferrovia à Anápolis. Nesse período, Anápolis se torna uma das cidades mais importantes da região por sua centralidade comercial e de serviços e comunicação com a região sudeste, e a rede urbana da região começa a se delinear. $\mathrm{O}$ 
período de 1930 e 1940, durante a Era Vargas, marca a construção de Goiânia, o início da industrialização do país, a criação da Colônia Agrícola Nacional de Goiás, CANG, com a expansão da fronteira agrícola, além do grande crescimento populacional, econômico e espacial de Anápolis.

Figura 3: Expansão urbana de Anápolis de 1879 a 2018.

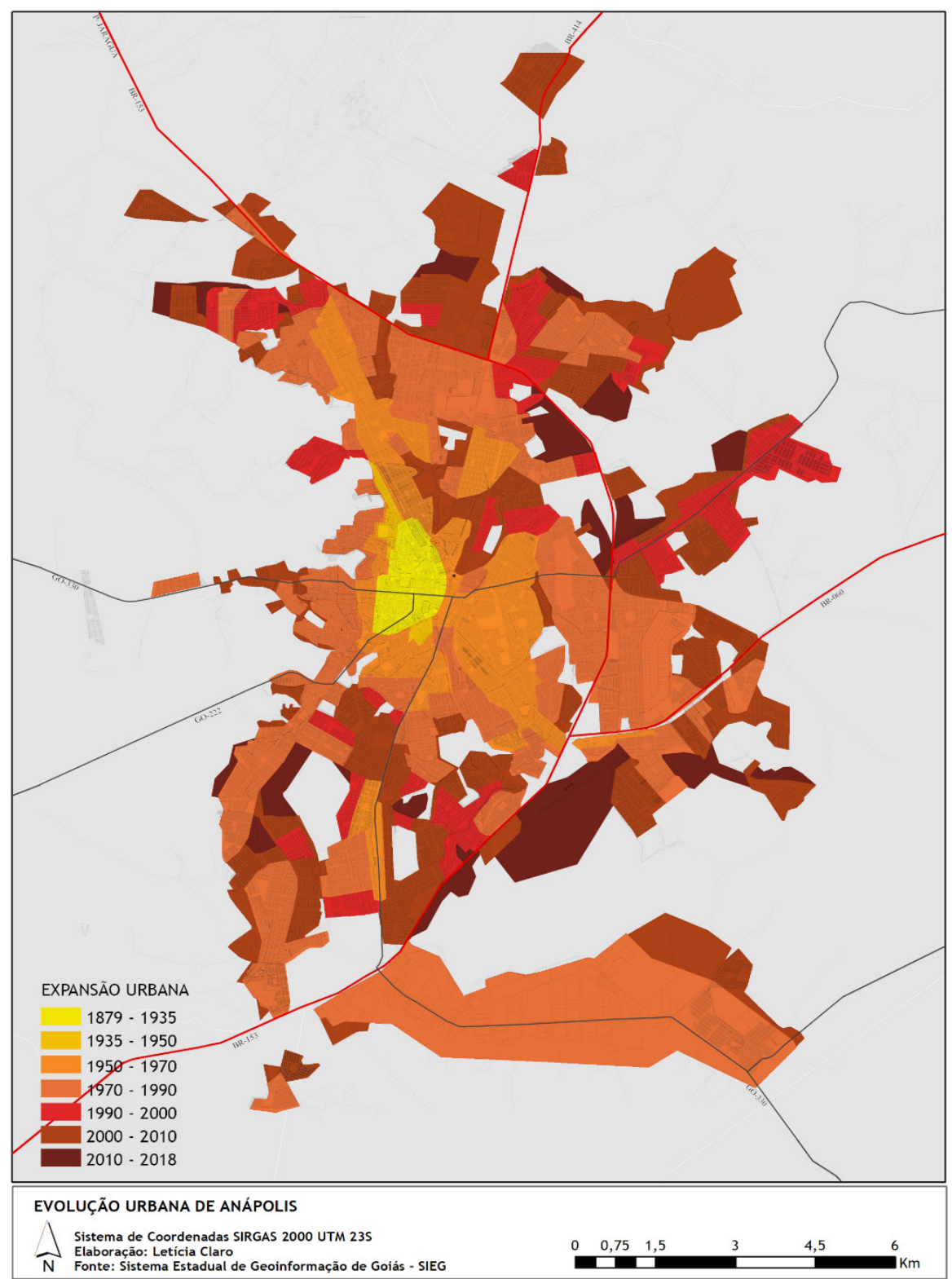

Fonte: BRITO, 2007.

O fim da ditadura varguista marca o retorno das famílias tradicionais goianas ao governo estadual. Esse período marca também o fim da Segunda Grande Guerra e a emergência de duas potenciais mundiais - Estados Unidos e União Soviética - e dois sistemas - capitalismo e socialismo. Esse período marcado pela dualidade política tem impacto local, abrindo caminho para uma crise política motivada pelo avanço comunista e também pelo aumento do número de organizações de setores populares na cidade. Para 
contribuir com o cenário de crise, na década de 1950 Goiânia se consolida como centralidade e Anápolis perde força e influência na rede urbana da região. No Quadro 1 é possível observar o resumo dos processos, estruturas, formas e funções da cidade nos períodos de 1887 a 1930 e de 1930 a 1950.

Quadro 1: análise espacial de Anápolis, GO, nos períodos de 1887-1930 e 1930-1950.

\begin{tabular}{|c|c|c|c|}
\hline \multicolumn{4}{|c|}{$1887-1930$} \\
\hline \multicolumn{4}{|c|}{ PROCESSO } \\
\hline \multicolumn{2}{|c|}{ CONTEXTO BRASIL/MUNDO } & \multicolumn{2}{|c|}{ CONTEXTO ANÁPOLIS } \\
\hline \multirow{2}{*}{\multicolumn{2}{|c|}{$\begin{array}{l}\text { República velha e coronelismo, Mineração do ouro } \\
\text { em Goiás, Esgotamento das lavras auríferas, } \\
\text { Expansão das rodovias e ferrovias }\end{array}$}} & \multirow{2}{*}{\multicolumn{2}{|c|}{\begin{tabular}{|l} 
Penetração de povoadores \\
Entreposto na rota comercial goiana
\end{tabular}}} \\
\hline & & & \\
\hline & & \multicolumn{2}{|c|}{ Características físicas propícias } \\
\hline \multicolumn{2}{|c|}{ ESTRUTURA } & FORMA & FUNÇÃ O \\
\hline AGENTES & IDEOLOGIAS & MARCOS & \\
\hline \multirow[b]{2}{*}{$\begin{array}{l}\text { Pequenos comerciantes, } \\
\text { exploradores }\end{array}$} & Coronelismo & Elevação a cidade & \multirow{3}{*}{$\begin{array}{l}\text { Agrícola e } \\
\text { pecuária de } \\
\text { subsistência e } \\
\text { de comércio } \\
\text { local }\end{array}$} \\
\hline & Religiosidade & \multirow{2}{*}{$\begin{array}{l}\text { Construção de } \\
\text { infraestruturas - } \\
\text { rodovias, } \\
\text { comunicação, edificios } \\
\text { públicos }\end{array}$} & \\
\hline $\begin{array}{l}\text { Oligarquias - famílias donas } \\
\text { de terra }\end{array}$ & & & \\
\hline \multicolumn{4}{|c|}{$1930-1950$} \\
\hline \multicolumn{4}{|c|}{ PROCESSO } \\
\hline \multicolumn{2}{|c|}{ CONTEXTO BRASIL/MUNDO } & \multicolumn{2}{|c|}{ CONTEXTO ANÁPOLIS } \\
\hline \multirow{5}{*}{\multicolumn{2}{|c|}{$\begin{array}{l}\text { Revolução de } 30 \text {, Marcha para Oeste, incentivos e } \\
\text { subsídios à industrialização, combate à oligarquia } \\
\text { caiadista, dinamização da agricultura (para } \\
\text { exportação), ascensão do nazismo, Golpe de } 37 \text {, } \\
\text { Segunda Grande Guerra }\end{array}$}} & \multirow{2}{*}{\multicolumn{2}{|c|}{\begin{tabular}{|l|} 
Relações comerciais com o Sudeste \\
Início da industrialização local ligada \\
ao beneficiamento de produtos \\
primários
\end{tabular}}} \\
\hline & & & \\
\hline & & \multicolumn{2}{|c|}{ Expansão da fronteira agrícola } \\
\hline & & \multicolumn{2}{|c|}{ Aumento populacional e migrações } \\
\hline & & \multicolumn{2}{|c|}{$\begin{array}{l}\text { Fortalecimento das atividades } \\
\text { comerciais }\end{array}$} \\
\hline \multicolumn{2}{|c|}{ ESTRUTURA } & FORMA & FUNÇÃO \\
\hline AGENTES & IDEOLOGIAS & MARCOS & \\
\hline \multirow{2}{*}{$\begin{array}{l}\text { Getúlio Vargas, Pedro } \\
\text { Ludovico, pequenos } \\
\text { comerciantes, produtores } \\
\text { rurais, ACIA }\end{array}$} & Modernidade & \multirow[b]{2}{*}{$\begin{array}{l}\text { Chegada da ferrovia, } \\
\text { conexões rodoviárias, } \\
\text { início da construção } \\
\text { de Goiânia, CANG, } \\
\text { criação da ACIA, } \\
\text { bancos }\end{array}$} & \multirow[b]{2}{*}{$\begin{array}{l}\text { Agricultura e } \\
\text { pecuária, início } \\
\text { da industria de } \\
\text { beneficiamento }\end{array}$} \\
\hline & & & \\
\hline
\end{tabular}

Fonte: modif. de CLARO, 2018.

Um fato que teve grande importância para a refuncionalização de Anápolis no final da década de 1950 foi a construção de Brasília e de um conjunto de infraestruturas que beneficiou diretamente a cidade goiana, confirmando a vocação de entreposto. As décadas de 1960 e 1970 representam o período de maior crescimento econômico, populacional e urbano de Anápolis, impulsionado pelos investimentos do BNH e SERFHAU - e pela 
construção de novos bairros e conjuntos habitacionais na cidade, pela construção da Base Aérea e Distrito Agroindustrial de Anápolis (DAIA), pela migração rural para a cidade devido à mecanização e tecnificação do campo - e pelo Milagre Econômico nos primeiros anos do governo militar.

Sob grande influência desse contexto de crescimento econômico e espacial, em 1969 é elaborado o primeiro plano diretor de Anápolis - o Plano Diretor Físico do Município de Anápolis. De acordo com esse plano, a organização física e racional da cidade garantirá o seu desenvolvimento econômico e social. Para isso dispõe de instrumentos e dispositivos como o abairramento, as áreas integradas, o sistema viário e o paisagismo. Esse plano é baseado nas ideias científicas da época, de que a racionalidade e o planejamento adequado levariam ao desenvolvimento e crescimento econômico.

A experiência de crescimento econômico e populacional desse período beneficiou atores da construção civil e também os donos de terra nos arredores da cidade, ambos contemplados e favorecidos pelo plano diretor de 1969. A não definição da área rural permitiu o parcelamento e transformação do uso do solo, o aumento do perímetro urbano e a não responsabilização do Estado do município como ator da urbanização. Esse cenário criou as bases para a expansão fragmentada de Anápolis à mercê do interesse do capital privado. Ainda, esse plano dá atenção especial ao sistema viário e à fluidez das estradas e vias do município, além de apontar as funções comercial varejista e de serviços como as principais fontes de renda do município e defender o desenvolvimento da função industrial no local.

Nos anos seguintes, novos atores são inseridos no cenário político local, com o DAIA e a Base Aérea fortalecendo atores como a antiga Associação Comercial e Industrial de Anápolis (ACIA). A década de 1980 marca um período de crise econômica em nível nacional: o aumento da informalidade urbana, o déficit habitacional e o fechamento de comércio e indústrias são exemplos da crise que assolou a cidade. Além disso, a crise política era um outro fator desse período de instabilidade. Em 1973 a cidade foi declarada área de segurança nacional e, desde então, mais de dez prefeitos foram nomeados em um intervalo de treze anos. Esse é o contexto de instabilidade econômica e política quando da elaboração do segundo plano diretor da cidade, o Plano Diretor de Anápolis, de 1985 (Quadro 2).

O plano diretor de 1985 é um plano compacto que se desenvolve em 20 artigos onde importantes pontos como informações sobre o zoneamento e uso e ocupação do solo são abordadoos de forma superficial para posterior detalhamento. Além disso o papel do Estado não fica claro e não é possível identificar claramente os atores beneficiados. Neste plano ainda permeia a ideia de que o planejamento físico pode proporcionar o desenvolvimento, porém, surge a figura da qualidade de vida como principal meta a ser atingida, apesar de não haver clareza em como atingi-la. Ainda não há uma definição para a área rural, o perímetro urbano será tratado em uma futura lei e, indiretamente, os mesmos atores do plano anterior são beneficiados. Enquanto retoma a discussão da importância do sistema viário com objetivo de organizar as funções da cidade e conferir fluidez à produção, há a valorização indireta dos setores da construção civil, comércio e transporte logístico na escala 
regional. Os anos seguintes não impedem uma expansão descontrolada e fragmentada da cidade, evidenciando que o plano de 1985 também não foi bem-sucedido em enfrentar o problema urbano daquela cidade.

Quadro 2: análise espacial de Anápolis, GO, nos períodos de 1950-1970 e 1970-1990.

\begin{tabular}{|c|c|c|c|}
\hline \multicolumn{4}{|c|}{$1950-1970$} \\
\hline \multicolumn{4}{|c|}{ PROCESSO } \\
\hline \multicolumn{2}{|c|}{ CONTEXTO BRASIL/MUNDO } & \multicolumn{2}{|c|}{ CONTEXTO ANÁPOLIS } \\
\hline \multirow{5}{*}{\multicolumn{2}{|c|}{$\begin{array}{l}\text { Deposição de Getúlio Vargas, Guerra Fria, } \\
\text { instabilidade política, assombro do comunismo, } \\
\text { emergência dos Estados Unidos e União Soviética, } \\
\text { Doutrina Truman, Governo Juscelino Kubitschek, } \\
\text { Conferência de Bretton Woods, planos } \\
\text { desenvolvimentistas, Golpe Militar de 1964, BNH e } \\
\text { SERFHAU }\end{array}$}} & \multicolumn{2}{|l|}{ Embates políticos } \\
\hline & & \multicolumn{2}{|c|}{$\begin{array}{l}\text { Crescimento do setores populares e } \\
\text { reação dos setores conservadores }\end{array}$} \\
\hline & & \multicolumn{2}{|c|}{$\begin{array}{l}\text { Concorrência de Goiânia e a } \\
\text { diminuição da influência na rede } \\
\text { urbana }\end{array}$} \\
\hline & & \multirow{2}{*}{\multicolumn{2}{|c|}{$\begin{array}{l}\text { Início dos serviços logísticos pela } \\
\text { consolidação da infraestrutura básica } \\
\text { Fornecimento de infraestrutura e mão } \\
\text { de obra para a construção de Brasília }\end{array}$}} \\
\hline & & & \\
\hline \multicolumn{2}{|c|}{ ESTRUTURA } & FORMA & FUNÇÃO \\
\hline AGENTES & IDEOLOGIAS & MARCOS & \\
\hline \multirow[b]{2}{*}{$\begin{array}{l}\text { Governo federal, vereadores } \\
\text { do município, comerciantes, } \\
\text { produtores rurais, ACIA, } \\
\text { BNH, donos de terra e } \\
\text { parceladores }\end{array}$} & Comunismo & \multirow[b]{2}{*}{$\begin{array}{l}\text { Construção de Brasília } \\
\text { e infraestruturas de } \\
\text { estruturação } \\
\text { (rodovias, } \\
\text { comunicação, } \\
\text { energia), Plano } \\
\text { Diretor de } 1969\end{array}$} & \multirow[b]{2}{*}{$\begin{array}{l}\text { Agricultura e } \\
\text { pecuária, } \\
\text { indústria de } \\
\text { beneficiamento }\end{array}$} \\
\hline & $\begin{array}{l}\text { Desenvolvimentismo } \\
\text { Racionalismo }\end{array}$ & & \\
\hline \multicolumn{4}{|c|}{$1970-1990$} \\
\hline \multicolumn{4}{|c|}{ PROCESSO } \\
\hline \multicolumn{2}{|c|}{ CONTEXTO BRASIL/MUNDO } & \multicolumn{2}{|c|}{ CONTEXTO ANÁPOLIS } \\
\hline \multirow{3}{*}{\multicolumn{2}{|c|}{$\begin{array}{l}\text { Choques do petróleo (1973 e 1979), falência do } \\
\text { Keynesianismo e emergência do neoliberalismo, fim } \\
\text { da Guerra Fria, independência dos países da Ásia e } \\
\text { África, era tecnocientífica, substituição das } \\
\text { importações, desconcentração industrial, I PND, II } \\
\text { PND, Milagre Econômico, década perdida (1980), } \\
\text { Constituição de 1988, redemocratização do Brasil }\end{array}$}} & \multicolumn{2}{|c|}{ Grande crescimento populacional } \\
\hline & & \multicolumn{2}{|c|}{$\begin{array}{l}\text { Investimentos do governo federal para } \\
\text { a industrialização local, pesquisas } \\
\text { agropecuárias }\end{array}$} \\
\hline & & \multicolumn{2}{|c|}{$\begin{array}{l}\text { Modernização da agricultura, produção } \\
\text { baseada em latifúndio e monocultura. } \\
\text { Expulsão da população rural }\end{array}$} \\
\hline & & \multicolumn{2}{|c|}{$\begin{array}{l}\text { Foco em Anápolis para receber o } \\
\text { contingente populacional que se } \\
\text { direcionada às grandes metrópoles }\end{array}$} \\
\hline \multicolumn{2}{|c|}{ ESTRUTURA } & FORMA & FUNÇÃO \\
\hline AGENTES & IDEOLOGIAS & MARCOS & \\
\hline \multirow{4}{*}{$\begin{array}{l}\text { Governo federal, grandes } \\
\text { latifundiários, donos de terra e } \\
\text { parceladores, ACIA }\end{array}$} & Planejamento & \multirow{4}{*}{$\begin{array}{l}\text { Base Aérea, Distrito } \\
\text { Agroindustrial de } \\
\text { Anápolis, Plano } \\
\text { Diretor de } 1985\end{array}$} & \multirow{4}{*}{$\begin{array}{l}\text { Indústria de } \\
\text { beneficiamento } \\
\text { comércio e } \\
\text { serviços de } \\
\text { transporte } \\
\text { logístico }\end{array}$} \\
\hline & Desenvolvimento & & \\
\hline & Industrialização & & \\
\hline & Racionalismo & & \\
\hline
\end{tabular}

Fonte: modif. de CLARO, 2018 
No final da década de 1980 e início dos anos 1990 o cenário de crise começa a mudar. Nesse período a Constituição Federal de 1988 é promulgada, inicia-se o processo de redemocratização do país, há a valorização da agenda ambiental, da multipolarização e da formação de blocos econômicos - no cenário nacional há a criação do Mercosul e exploração dos corredores de exportação Esse é o período da abertura dos mercados com foco em políticas liberais e também da irradiação do meio técnico-científico-informacional.

Uma onda tecnológica redefine os conceitos de fluidez, cenário do terceiro plano diretor de Anápolis - o Plano Diretor Urbano de Anápolis, de 1992. Esse plano inaugura importantes características do território e estratégias de ordenamento, como os eixos estruturadores, reconhece novas centralidades, as estratégias de expansão, diferentes zoneamentos de acordo com a dinâmica local, introduz a modalidade de loteamento de interesse social, trata da proteção do meio ambiente e, pela primeira vez, define o uso rural.

O objetivo do plano de 1992 é ordenar o crescimento urbano e o espaço intraurbano reconhecendo problemas gerados pelo modelo de expansão do passado e oferecendo subsídios para o enfrentamento desses problemas. O grande diferencial desse plano é o reconhecimento de novas centralidades com diferentes vocações - comercial e de serviços com abrangência local e regional, educacional e industrial - da definição do uso da área rural e do papel dos eixos estruturadores. Esse plano entende a multiatorialidade que faz uso do território, também entende desenvolvimento como um conjunto econômico, social e ambiental, e dá atenção especial às funções atacadista/logística, serviços educacionais e industrial.

A partir da década de 1990 o setor de transporte logístico anapolino vem ganhando força, paralelamente à especialização do DAIA com a instalação do Polo Farmoquímico, à chegada da montadora CAOA/Hyundai e ao fortalecimento das relações de Anápolis no eixo Brasília-Goiânia. O início dos anos 2000 é marcado por uma nova onda de crescimento econômico agora com foco na especialização da indústria e exploração do setor de transporte logístico. O Porto Seco, o Polo Farmoquímico e o agronegócio são importantes atores que serão beneficiados na cena anapolina. A lei que aprova a criação da Plataforma Logística Multimodal de Anápolis é aprovada em 2001, confirmando a exploração da localização estratégica da cidade para o desenvolvimento da função de transporte logístico; 2001 é o ano também da aprovação do Estatuto da Cidade, instrumento que regulamenta os artigos 182 e 183 da Constituição Federal de 1988 e uma das bases para a elaboração do primeiro Plano Diretor Participativo do Município de Anápolis em 2006.

O plano de 2006 resgata a multiplicidade de usos do município trazida pelo plano de 1992 e foca no setor de transporte logístico, setor industrial e comercial, além de dedicar atenção especial para a interdependência campo-cidade. O plano de 2006 reconhece a ação social, a multiatorialidade e planejamento compartilhado, explora a questão ambiental pelo reconhecimento de áreas sensíveis do território e proposição de estratégias de qualificação ambiental. Esse plano baseia-se no equilíbrio das dimensões social, econômica e ambiental e busca balancear a ação dos agentes econômicos e sociais, aqui o Estado é visto como defensor dos direitos sociais. Além dos diferentes atores, os meios urbano, rural e natural se complementam e o plano diretor é quem faz a mediação e diálogo com cada dimensão. 
Apesar de evidenciar aspectos da qualidade de vida e bem-estar da população influências do Estatuto da Cidade - o elemento central do plano de 2006 é o mercado. O equilíbrio das várias dimensões da cidade é necessário para o município se desenvolver, porém, o desenvolvimento econômico é primordial para impulsionar o desenvolvimento social. Para atingir tal desenvolvimento econômico, o plano define as áreas estratégicas: DAIA, Plataforma Logística Multimodal, universidades e faculdades, Avenida Brasil, BR414, BR-060, GO-330, GO-222 e GO-560.

Ainda sobre a promoção econômica do município, o plano dedica um capítulo exclusivo para a temática com objetivo de dinamizar a economia local e promover melhor qualidade de vida pela ação compartilhada do Estado com a comunidade e setores produtivos. Há atenção especial para a melhoria da infraestrutura com objetivo de tornar a cidade mais competitiva. Nesse aspecto a Plataforma Logística é um elemento chave, sendo necessária sua implantação, além da criação de um polo tecnológico. Esse plano explicita a necessidade de explorar a potencialidade logística de Anápolis em paralelo com a qualificação da população e incentivos ao setor tecnológico. Essas características se aproximam com a forte presença e atuação do Polo Farmoquímico e Porto Seco no processo de tomada de decisão local e também evidenciam como os incentivos dos anos anteriores para a criação dos corredores de exportação transformaram a visão da cidade, agora com foco no transporte logístico.

No período de 2000 a 2010 (Quadro 3) Anápolis passa por um intenso processo de transformação da sua forma urbana, conformando-se como um dos maiores canteiros de obras do país. Obras do trecho Norte-Sul da ferrovia, obras de infraestrutura viária, da construção da Plataforma Logística e da adequação do Aeroporto de Cargas e grandes empreendimentos residenciais são exemplos de obras que ocorriam a todo o vapor na cidade. O Programa de Aceleração do Crescimento e o Programa Minha Casa Minha Vida são os principais responsáveis por delinear esse cenário. 
Quadro 3: análise espacial de Anápolis, GO, nos períodos de 1990-2000 e 2000-2010.

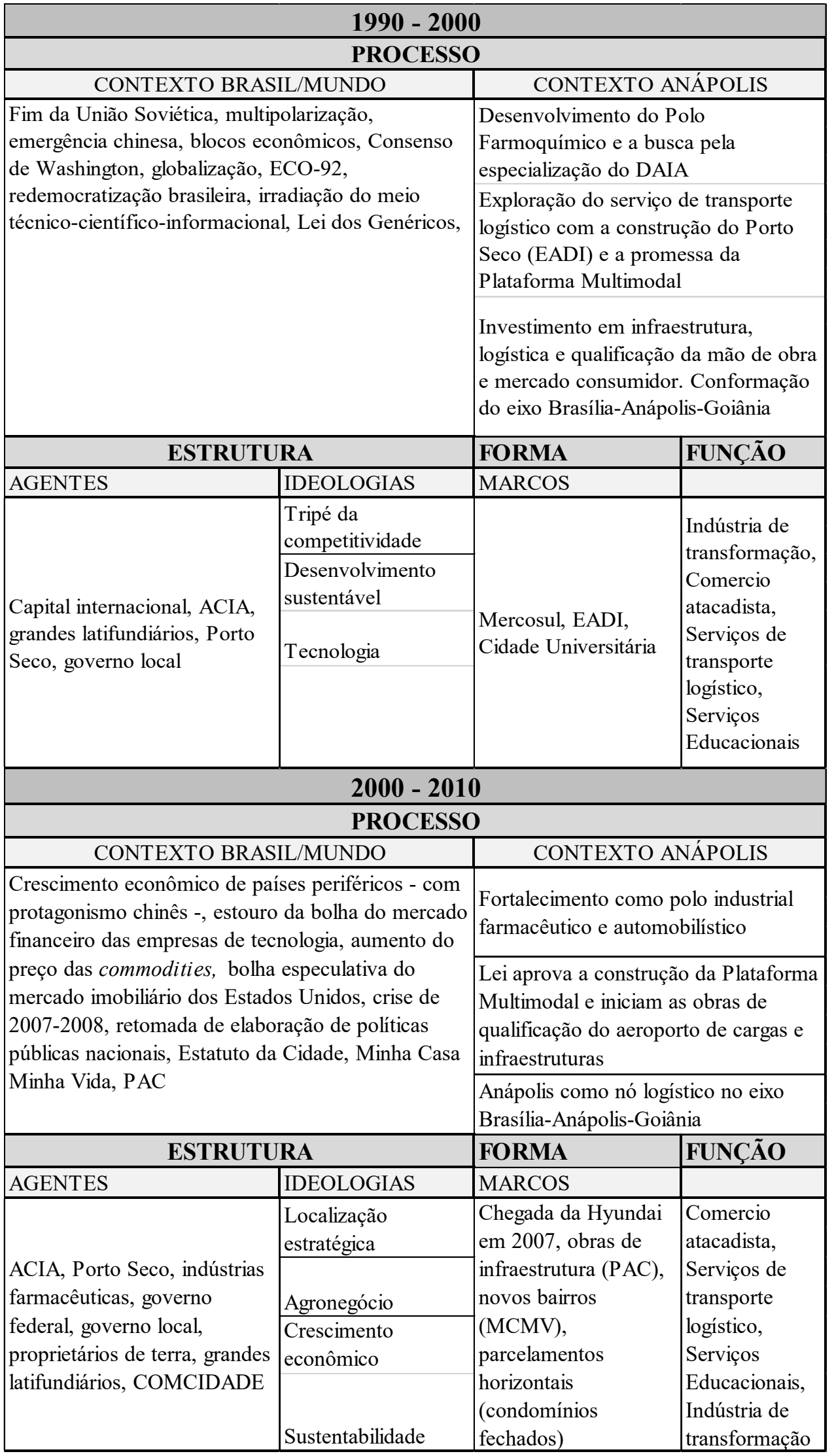

Fonte: modif. de Claro, 2018. 
A partir de 2010 o cenário de crescimento se reverte (Quadro 4). A crise mundial atinge o país e a queda do preço das commodities afeta Anápolis diretamente. Em 2015 a prefeitura anuncia uma série de cortes, os jornais noticiam problemas da infraestrutura básica - sistema viário, energia e esgoto. A crise também afeta o DAIA e outras indústrias e comércio locais. Além da crise econômica, a crise política que varre o país também atinge Anápolis e os primeiros protestos ganham as ruas. É nesse contexto de crises que o Plano Diretor Participativo do Município de Anápolis é elaborado em 2016 buscando apaziguar o descontentamento da população e setores produtivos.

Nesse momento, a população sente os efeitos da crise por meio do aumento do desemprego e pela dúvida da finalização das obras dos conjuntos habitacionais do Programa Minha Casa Minha Vida. Já as elites produtivas são afetadas pelo corte de verbas e investimentos, pelo excesso de burocracia e, principalmente, pela paralização das obras iniciadas nos anos anteriores, como os viadutos dos principais eixos viários, a infraestrutura de drenagem pública e melhoria da capacidade energética. Esses descontentamentos, tanto das elites produtivas quanto da população, são absorvidos pelo plano de 2016 que dá continuidade ao plano de 2006 no sentido da consolidação de Anápolis como polo industrial, logístico e tecnológico.

A base desse plano são os objetivos e diretrizes do Estatuto da Cidade e o seu principal foco é o pleno desenvolvimento das funções sociais da cidade e da propriedade. Os objetivos do plano deixam clara a intenção de unir estratégias de uso e ocupação do solo, de uso sustentável do meio ambiente, de valorização do patrimônio, de desenvolver as funções sociais da cidade e também de melhorar a gestão do plano diretor. O elemento central é a sociedade e o plano inaugura o uso de instrumentos para a defesa da função social da cidade e da propriedade, resgatados do Estatuto da Cidade. Também trata de mobilidade e acessibilidade e de estratégias de desenvolvimento social pelo lazer, educação, cultura e saúde.

Apesar do foco social, as elites econômicas também são contempladas. O plano dá atenção especial ao setor industrial, logístico e tecnológico, vistos como relevantes elementos competitivos. O plano reforça também a necessidade de adequar a infraestrutura básica, especialmente a capacidade do setor energético e os gargalos do sistema viário, de integração do município com as outras esferas de governo, de desburocratizar a máquina pública e facilitar a criação de novos empreendimentos, e de estabelecer parcerias entre setor produtivo e as faculdades e universidades locais.

Esse plano propõe ainda a criação de um Complexo Municipal de Distritos Sustentáveis - pela descrição, algo semelhante à uma expansão do Distrito Agroindustrial - e propõe a criação de uma política de incentivos fiscais visando ao desenvolvimento tecnológico. As funções privilegiadas pelo plano de 2016 ainda são a industrial, logística e de serviços ligados ao setor tecnológico. 
Quadro 4: análise espacial de Anápolis, GO, nos períodos de 2010-2018.

\begin{tabular}{|c|c|c|c|}
\hline \multicolumn{4}{|c|}{$2010-2018$} \\
\hline \multicolumn{4}{|c|}{ PROCESSO } \\
\hline \multicolumn{2}{|c|}{ CONTEXTO BRASIL/MUNDO } & \multicolumn{2}{|c|}{ CONTEXTO ANÁPOLIS } \\
\hline \multirow{5}{*}{\multicolumn{2}{|c|}{$\begin{array}{l}\text { Crise mundial atinge o Brasil, abalos à estrutura da } \\
\text { União Europeia, Brexit, medidas neoliberais para } \\
\text { enfrentar a crise, temor do boom de créditos da } \\
\text { China, ofensiva russa, disputas comerciais entre os } \\
\text { Estados Unidos e a China, avanço da extrema } \\
\text { direita, crise de refugiados, crise financeira nos } \\
\text { países da América do Sul, queda no preço das } \\
\text { commodities, crise política no Brasil, impeachment } \\
\text { da presidente Dilma Rousseff, Operação Lava Jato, } \\
\text { protestos contra a corrupção }\end{array}$}} & \multicolumn{2}{|c|}{$\begin{array}{l}\text { Do boom da economia local, com } \\
\text { vertiginosos aumentos de arrecadação } \\
\text { e produtividade à crise econômica }\end{array}$} \\
\hline & & \multicolumn{2}{|c|}{ Previsão da expansão do DAIA } \\
\hline & & \multicolumn{2}{|c|}{$\begin{array}{l}\text { Descontentamento da classe industrial } \\
\text { com a paralização das obras e } \\
\text { problemas de infraestrutura }\end{array}$} \\
\hline & & \multicolumn{2}{|c|}{$\begin{array}{l}\text { Gargalos nos serviços de água, esgoto, } \\
\text { iluminação, sistema viário e } \\
\text { paralização das obras de infraestrutura }\end{array}$} \\
\hline & & \multicolumn{2}{|c|}{$\begin{array}{l}\text { Crise nos principais agentes } \\
\text { econômicos - Hyundai e Grupo } \\
\text { Naoum }\end{array}$} \\
\hline \multicolumn{2}{|c|}{ ESTRUTURA } & FORMA & FUNÇÃO \\
\hline AGENTES & IDEOLOGIAS & MARCOS & \\
\hline \multirow{3}{*}{$\begin{array}{l}\text { Grupo Naoum, Hyundai, } \\
\text { ACIA, Porto Seco, indústrias } \\
\text { farmacêuticas, governo local, } \\
\text { grandes latifundiários, } \\
\text { COMCIDADE }\end{array}$} & Tecnologia & \multirow{3}{*}{$\begin{array}{l}\text { Ferrovia Norte-Sul, } \\
\text { Viaduto do DAIA, } \\
\text { Viaduto da Av. } \\
\text { Universitária, } \\
\text { paralisação das obras } \\
\text { do aeroporto, } \\
\text { Plataforma } \\
\text { Multimodal }\end{array}$} & \multirow{3}{*}{$\begin{array}{l}\text { Comercio } \\
\text { atacadista, } \\
\text { Serviços de } \\
\text { transporte } \\
\text { logístico, } \\
\text { Serviços } \\
\text { Educacionais, } \\
\text { Indústria de } \\
\text { transformação }\end{array}$} \\
\hline & Corrupção & & \\
\hline & & & \\
\hline
\end{tabular}

Fonte: modif. de Claro, 2018

\section{CONCLUSÕES}

Traçar o panorama histórico em paralelo com as características dos planos diretores permite e compreender como a refuncionalização ocorre na cidade de Anápolis. Este processo passou pela exploração comercial e de serviços incipientes de escoamento da produção local, por serviços ligados à construção civil - com a construção de Brasília; pela especialização do setor industrial - farmoquímico e automobilístico; por serviços educacionais e de serviços de transporte logístico em escala regional e, posteriormente, escala nacional e internacional.

É possível observar também o claro direcionamento dos dois últimos planos diretores rumo ao desenvolvimento e exploração do setor tecnológico com a participação de faculdades, universidades e empresas locais. Ainda, traçar o panorama permitiu observar a mudança do elemento central defendido pelo plano - mercado e sociedade, geralmente relacionada a aspectos dos processos sociais. 
Os planos de 1985 e 2016 têm a sociedade como elemento central, o primeiro estava inserido em um contexto de crise social e política do fim do período militar, o segundo em uma crise econômica e política que assolou o país e culminou no impeachment da presidente Dilma Rousseff. Os planos de 1969, 1992 e 2006 têm o mercado como elemento central.

O plano de 1969 se insere no contexto de boom de crescimento urbano e econômico de Anápolis, enquanto o plano de 1992 está inserido numa onda neoliberal de blocos econômicas e trocas comerciais em escala internacional. Já o plano de 2006 se insere em uma nova onda de crescimento econômico, intensas trocas comerciais com o mercado chinês e o êxtase do país por não ter sido afetado pela crise que começa a se desenhar na Europa e nos Estados Unidos.

Os planos evidenciam também os atores econômicos privilegiados. O plano de 1969 privilegia serviços e comércio e começa a direcionar para o setor industrial; o plano de 1985 presta serviço aos setores da construção civil e de transporte logístico para escoamento da produção local. O plano de 1992 privilegia o setor de comércio e serviços e inaugura a valorização dos serviços educacionais e direcionamento para o transporte logístico em escala nacional e internacional. O plano de 2006 se mostra bastante complementar ao anterior, dando continuidade ao direcionamento ao setor de transporte logístico em maior escala e introduz o setor tecnológico como importante apoio para a competitividade do da indústria local. Já o plano de 2016 dá atenção às funções industrial, logística e de serviços tecnológicos.

Outra característica importante dos planos que tem relação direta com o processo de refuncionalização desta cidade é a mudança da visão do território-palco e da ideologia de ordenamento e desenvolvimento. Aos poucos a multiatorialidade é inserida nos planos, e o papel desses atores para o desenvolvimento passa a ser reconhecido. A visão do território também muda, novas centralidades, eixos estruturadores e áreas estratégicas são reconhecidas, além da interação do ambiente construído com o meio social e natural, e com as atividades do campo.

Ainda, os dois últimos planos - 2006 e 2016 - inauguram a modalidade participativa e introduzem instrumentos para enfrentar as desigualdades socioespaciais, defendem a produção compartilhada do espaço e começam a delinear caminhos para maior permeabilidade do Estado e para a participação de diferentes atores na elaboração de políticas públicas.

O exercício dessa pesquisa, de explorar a história narrada pelos planos diretores e observar o caminho da refuncionalização dentro desses planos, permite explorar como as políticas públicas são utilizadas no direcionamento de usos do território. Em Anápolis, os planos diretores tiveram um importante papel na refuncionalização para a manutenção desta cidade como centralidade em sua rede urbana, adequando o território às imposições da escala interurbana. Ainda, esse exercício, foi importante para reforçar o conceito de que as políticas são intencionais e temporais, resultado de conflitos e disputas de interesse, utilizadas para legitimar a ação de determinados grupos. 


\section{REFERÊNCIAS}

ALLMENDINGER, P. Planning Theory. 2.ed. Basingstoke: Palgrave Macmillan, 2009.

ANÁPOLIS. Lei de $\mathbf{n}^{0} 160$ de 26 de setembro de 1969. Institui o Plano Diretor Físico do Município de Anápolis, suas formas ordenadoras e disciplinadoras e dá outras providências. Anápolis: [s.n.], 1969.

ANÁPOLIS. Lei $\mathbf{n}^{0} \mathbf{1 3 2 6}$ de 24 de setembro de 1985. Dispõe sobre a Lei Plano Diretor de Anápolis e dá outras providências. Anápolis: [s.n.], 1985.

ANÁPOLIS. Lei de n ${ }^{\circ} 2077$ de 22 de dezembro de 1992. Aprova o Plano Diretor Urbano de Anápolis e dá outras providências. Anápolis: [s.n.], 1992.

ANÁPOLIS. Lei Complementar $\mathbf{n}^{0} 128$ de 10 de outubro de 2006. Dispõe sobre o Plano Diretor Participativo do Município de Anápolis, estado de Goiás. Anápolis: [s.n.], 2006.

ANÁPOLIS. Lei Complementar $\mathbf{n}^{\circ} 349$ de 7 de julho de 2016. Dispõe sobre o Plano Diretor Participativo do Município de Anápolis. Anápolis: [s.n.], 2016.

BRITO, R.M.D.F. A. A evolução e produção da estrutura urbana em Anápolis - 1993 a 2004: estudo da interferência das gestões municipais. Goiânia, 2007. Dissertação (Mestrado em Geografia) - Universidade Federal de Goiás, UFGO.

CLARO, L.P. dos P. O processo de refuncionalização em Anápolis a partir dos Planos Diretores de 1969 a 2016. Brasília, 2018. Dissertação (Mestrado em Desenvolvimento, Sociedade e Cooperação Internacional) - Universidade de Brasília, UnB.

CORRÊA, R.L. Cidades médias e rede urbana. In: SILVA, W. R. D.; SPÓSITO, M.E.B. Perspectivas da Urbanização: reestruturação urbana e das cidades. Rio de Janeiro: Consequência Editora, 2017

GOMES, M.D.S.; STEINBERGER, M.; BARBOSA, R.P. O potencial político da categoria 'território usado'. In: STEINBERGER, M. (Org.) Território, Estado e políticas públicas espaciais. Brasília: Ler Editora, 2013. p. 65-88.

GOTTDIENER, M. A produção social do espaço urbano. São Paulo: Ed. USP, 1997.

IPEA - Instituto de Pesquisa Econômica Aplicada. Caracterização e tendências da rede urbana do Brasil: Desenvolvimento Regional e Estruturação da Rede Urbana. Brasília, 2002.

LASCOUMES, P.; LE GALES, P. Sociologia da ação pública. Maceió: Ed. UFAL, 2012.

SANTOS, M. Espaço e método. São Paulo: Nobel,1985.

SANTOS, M. A Natureza do Espaço. 4.ed. São Paulo: Ed. USP, 2014.

SANTOS, M.; SILVEIRA, M.L. O Brasil - território e sociedade no início do século XXI. 5. ed. Rio de Janeiro: Record, 2003.

SANTOS JUNIOR, O.A. dos.; MONTANDON, D.T. Os Planos Diretores Municipais Pós-Estatuto da Cidade: balanço crítico e perspectivas. Rio de Janeiro: Letra Capital, 2011.

SILVEIRA, M.L. Cooperação e conflito na cidade média: algumas reflexões acerca do fenômeno urbano na globalização. In: SILVA, R.D.; SPÓSITO, M.E.B. Perspectivas da Urbanização: reestruturação urbana e das cidades. Rio de Janeiro: Consequência, 2017. p. 39-52.

SPÓSITO, M.E.B.; GÓES, E.M. Espaços Fechados e Cidades: insegurança urbana e fragmentação socioespacial. São Paulo: Ed. UNESP, 2013.

VILLAÇA, F. Uma contribuição para a história do planejamento urbano no Brasil. In: DEÁK, C.; SCHIFFER, S. R. Planejamento urbano no Brasil. São Paulo: Ed. USP, 2004.

Data de submissão: 28/fev./2019

Data de aceite: 21/set./2019 